Correction

\title{
Correction: Bueckert et al. Infectivity of SARS-CoV-2 and Other Coronaviruses on Dry Surfaces: Potential for Indirect Transmission. Materials 2020, 13, 5211
}

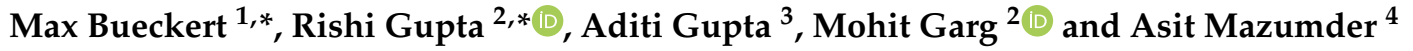 \\ 1 Department of Biochemistry \& Microbiology, University of Victoria, 3800 Finnerty Road, \\ Victoria, BC V8P 5C2, Canada \\ 2 Department of Civil Engineering, University of Victoria, 3800 Finnerty Road, Victoria, BC V8P 5C2, Canada; \\ mgarg@uvic.ca \\ 3 Mearns Centre for Learning-McPherson Library, University of Victoria, 3800 Finnerty Road, \\ Victoria, BC V8P 5C2, Canada; aditig@uvic.ca \\ 4 Department of Biology, University of Victoria, 3800 Finnerty Road, Victoria, BC V8P 5C2, Canada; \\ mazumder@uvic.ca \\ * Correspondence: maxbueckert@uvic.ca (M.B.); guptar@uvic.ca (R.G.)
}

check for updates

Citation: Bueckert, M.; Gupta, R.; Gupta, A.; Garg, M.; Mazumder, A. Correction: Bueckert et al. Infectivity of SARS-CoV-2 and Other Coronaviruses on Dry Surfaces: Potential for Indirect Transmission. Materials 2020, 13, 5211. Materials 2021, 14, 2816. https://doi.org/ 10.3390/ma14112816

Received: 9 May 2021

Accepted: 20 May 2021

Published: 25 May 2021

Publisher's Note: MDPI stays neutral with regard to jurisdictional claims in published maps and institutional affiliations.

Copyright: (c) 2021 by the authors. Licensee MDPI, Basel, Switzerland. This article is an open access article distributed under the terms and conditions of the Creative Commons Attribution (CC BY) license (https:/ / creativecommons.org/licenses/by/ $4.0 /)$.
The authors wish to make the following corrections to this paper [1]:

1. Throughout the paper's text and in the table, "HCoV-299E" is referred to a few times. However, this has been changed and referred to as "HCoV-229E".

2. Citation [60] (Ye, Y.; Ellenberg, R.M.; Graham, K.E.; Wigginton, K.R. Survivability, Partitioning, and Recovery of Enveloped Viruses in Untreated Municipal Wastewater. Environ. Sci. Technol. 2016, 50, 5077-5085, doi:10.1021/acs.est.6b00876.) should be changed to the following article "Gundy, P.M.; Gerba, C.P.; Pepper, I.L. Survival of Coronaviruses in Water and Wastewater. Food Environ. Virol. 2009, 1, 10".

The authors would like to apologise for any inconvenience caused to the readers by these changes.

\section{Reference}

1. Bueckert, M.; Gupta, R.; Gupta, A.; Garg, M.; Mazumder, A. Infectivity of SARS-CoV-2 and Other Coronaviruses on Dry Surfaces: Potential for Indirect Transmission. Materials 2020, 13, 5211. [CrossRef] [PubMed] 